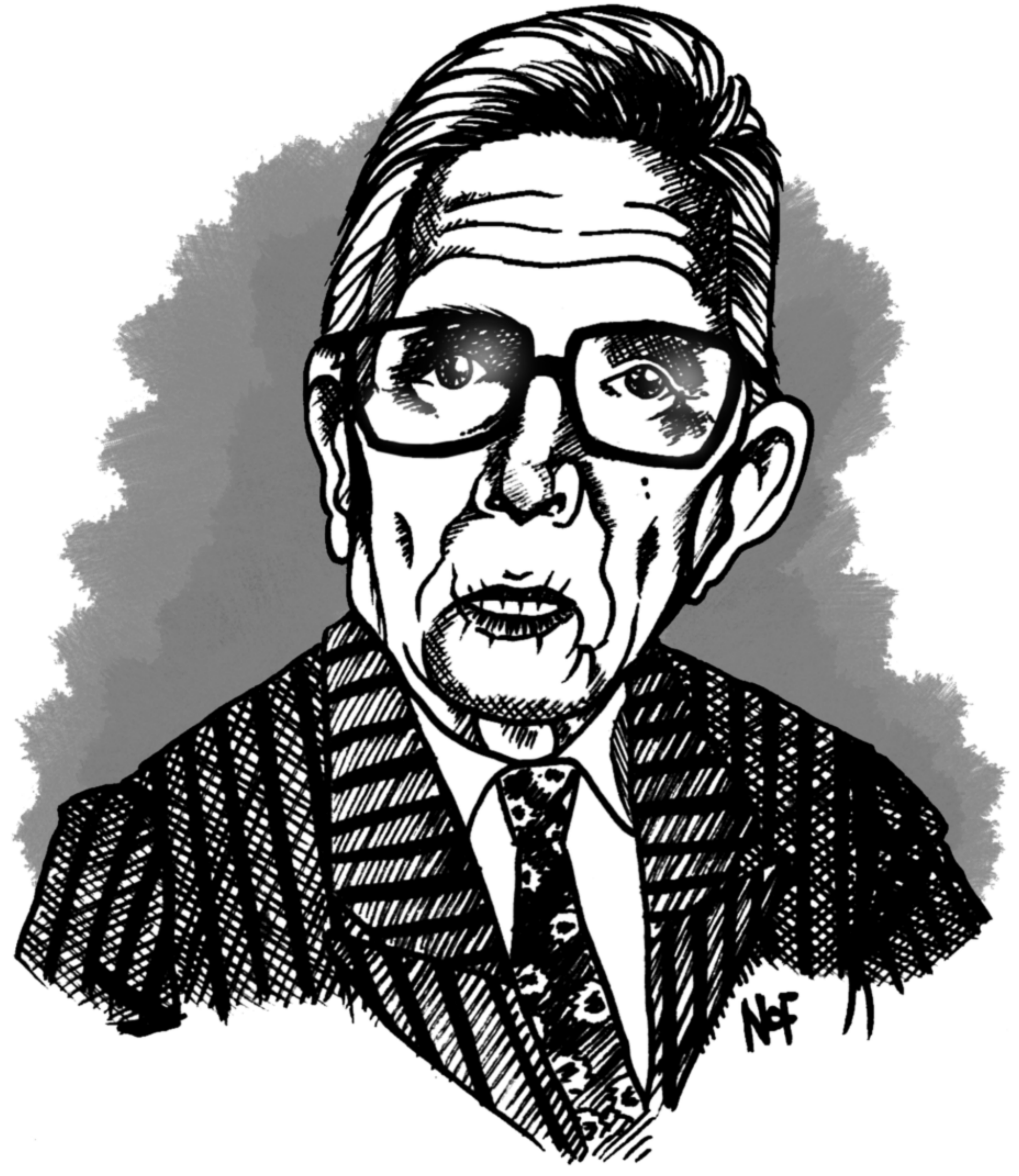




\section{Gustavo Alfredo}

\section{Jácome}

\section{-Un siglo de sabidurías literarias-*}

\section{Marcelo Valdospinos Rubio}

"Que descubran que hay poesía en todas partes, aunque no siempre hayan poemas"

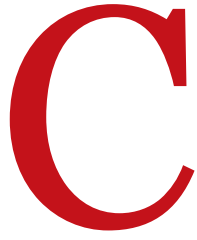

uando la palabra trasborda los límites de lo concreto se vuelve poesía. Ella habita en un entorno familiar: poesía, poemas y poetas. La poesía es una larga confesión con el paisaje existencial y el paisaje íntimo. Y está al alcance de todos, allí sueños y frustraciones surgen de la cotidianidad vivida. El poema es un texto donde los versos se encadenan unos a otros, urdimbres de amores y desamores, de dioses y demonios, de dialécticas. 
Y, el poeta, un ser especial que descubre rayos de sol en la oscuridad, poseedor de una mirada penetrante que atraviesa la realidad por los mínimos detalles. Dice Clara Luz Zúñiga, que la tarea del poeta es "Recuperar el sentido del verbo, hacer que los hombres vuelvan a ser símbolo de identidad, que vuelvan a evocar y traer realidades del recuerdo, que descubran que hay poesía en todas partes, aunque no siempre hayan poemas". O como afirma Max Neef "Unos hacen poesía y otros son poetas; unos hacen música y otros son músicos; unos hacen el amor y otros están enamorados". Los poetas son: vínculos entre Dios y el hombre. Entre el hombre y el universo. Entre el hombre y el amor. Entre el hombre y el hambre. Entre el hombre y la angustia.

\section{"Menos gramática y más lengua"}

¿Qué poetas sobresalieron en el itinerario generacional del siglo XX en Otavalo? A vuelo de pájaro señalemos que en los Vasconcelos destacan Luis Enrique Cisneros, Guillermo Garzón Ubidia y Francisco H. Moncayo. En los Normalistas, surge la figura más grande de la poesía otavaleña, Gustavo A. Jácome. Además, Gonzalo Benítez, Carmen Carrillo de Ubidia. En el Otavalo Institucional, Lola Orbe Carrera, Luis Honorio Ruiz, Oscar Silva, Jaime Valdospinos y Daniel Suárez. En el grupo de Síntesis, Álvaro San Félix. En los Atabalibas, Juan F. Ruales. Y, contemporáneos, jóvenes promesas, como Fernando Bonilla y Gaby Ponce, entre tantos otros. Las revistas y periódicos de la ciudad guardan versos furtivos de destacados intelectuales. De Isaac J. Barrera, Aurelio Ubidia, Víctor G. Garcés, Gonzalo Rubio O., Germán Cifuentes, Plutarco Cisneros A., con buena poesía. En Otavalo la corriente generalizada no ha sido la poesía, sino la literatura de reivindicación social, la antropología, la sociología, la educación y la política.

Gustavo A. Jácome es alfarero de la palabra docta, sabio en lenguajes, hombre austero, moral y a veces muy duro. Es quien más ha contribuido al desarrollo del castellano en el país. Desde la cátedra y desde sus libros especializados en gramática escolar, literatura secundaria y estilística universitaria. Dice "la clave para aprender castellano, es no concentrarse en la gramática, sino enseñar a los educandos a hablar, a escribir y a leer". Permanentemente recuerda a Unamuno "Menos gramática y más lengua”.

\section{"Me hizo a su imagen y semejanza"}

En el 2012 se celebra el Centenario de nacimiento del eximio y laureado poeta Gustavo A. Jácome -doctor en otavaleñidades- hijo de José A. Jácome y Rosa Jácome Terreros. Entre diez hijos, fue el único varón. Casado con doña Emperatriz Lovato, ya fallecida. Tiene cuatro hijos. Su espejo existencial fue Fernando Chaves Reyes. "Me hizo a su imagen y semejanza", declaró más de una vez.

Cultivó con excelencia la docencia. Irrumpió en la novela, el cuento, la estilística, la gramática, la ortografía. Ideológicamente se ubicó en la izquierda, siempre comprometido con la patria, con los maestros, con los niños, con su tierra. Con la palabra y los libros. Con la oratoria y la profundidad del verso.

Precisaba sobre sus novelas: "¿por qué se fueron las garzas? tiene una base real, el matrimonio de un indígena, que estudió en los Estados Unidos, y una norteamericana, que lo sabía todo de Otavalo, lo demás es imaginario". Y sobre los "Puchos Remaches", dijo "los Remaches eran indios salteadores de caminos, fusilados en 1896 en la plaza de Otavalo, en presencia de sus hijos, a quienes se les llamó luego puchos Remaches. Sus descendientes son los ladrones que están infestando este país. Alrededor de este tema nace la novela”. 
Como Miembro de la Academia Ecuatoriana de la Lengua, ha sido un permanente crítico de los americanismos y su política ortográfica.

Bajo su égida e inteligencia integramos el Comité Pro-Sesquicentenario de Otavalo. Sesiones de la memoria y del afecto. Diálogos sobre la trayectoria histórica de la ciudad. No se lograron los objetivos a plenitud, pero fue una experiencia maravillosa con el pasado y las raíces interculturales

\section{"Luz primera de mis ojos, de mi vida la inicial..."}

Creador de bellas estampas de la ciudad, que quedaron impregnadas en sus "Acuarelas" y "Viñetas". Su poesía infantil toma esplendor nacional, por ser bella, traslúcida y motivadora. Miles de niños ecuatorianos cursaron su escolaridad bajo el mágico encanto de las rimas de Gustavo A. Jácome. Su palabra lírica está insuflada de lúdica y ternura. Su poesía infantil es una ronda, en permanente viaje hacia la naturaleza, las nubes y las estrellas. En esta línea su libro más emblemático es "Luz y Cristal", poemas con olor a escuela, a plastilina, a recreo, bañados de pureza e inocencia:

“Topa, topa, corderito, / corderito juguetón. / iQué mullido y qué bonito / es tu cándido vellón!”.

Y a la madre, en estrofa tierna, le canta:

"Luz primera de mis ojos, / de mi vida la inicial. / Soy un eco pequeñito / de tu latido cordial."

Y en su opúsculo "Palabras para jugar", la rima sigue caudalosa: "En la playa me he encontrado / un caracol, al acaso / en su interior decorado / con la lumbre del ocaso".

Y otro, "Hola, lorito loro, / fonógrafo vegetal, / ¿Está rayado tu disco / o tu memoria anda mal?".

\section{"Quererla como a mujer de noche entera"}

Siempre Otavalo estuvo presente e invariable en su retina. En sus Viñetas está inscrito su testamento de amor a la ciudad. Enamorado, lleno de ausencias, le canta: "Yo retornaba a tu lado después de cada trimestre estudiantil. / Y te encontraba, aquí y allá como siempre, salpicada de lagunas. / Otras veces, aromada de musgos navideños, frutecida de maizales, / morena de montes, valles y praderas tendidas al sol". Y, define "Otavaleñidad: perdido enamoramiento entre un hombre y su tierra. Los ojos en los ojos."

O, con rasgo erótico, en frase que descubre su corazón amante, le dice "A Otavalo hay que quererla como a mujer de noche entera”.

Durante un siglo Gustavo A. Jácome ha sido espejo permanente en el sacrificio, en el talento, en la ética y en su invariable terrigenismo.

\section{Bibliografía:}

- Jácome, Gustavo A.: Luz y Cristal, CCE. Palabras para Jugar, Alfaguara, 2001

- Sarance. Número Extraordinario VII, IOA, 1992

- Villacís M., Rodrigo. Palabras Cruzadas. BC, del Ecuador, 1988 